\title{
ROLE OF LEVOFLOXACIN FOR TREATMENT OF CHRONIC SUPPURATIVE OTITIS MEDIA: SAMPLE OF IRAQI PATIENTS
}

\author{
SAFAA SAHIB NAJI SULTAN ${ }^{1}$, MALATH AZEEZ ALSAADY ${ }^{2 *}$ \\ ${ }^{1}$ Department of Surgery, College of Medicine, University of Babylon, Iraq. ${ }^{2}$ Department Pharmacology and Toxicology, College of Dentistry, \\ University of Babylon, Iraq. Email: malathazeez1122@gmail.com \\ Received: 25 February 2017, Revised and Accepted: 09 June 2017
}

\section{ABSTRACT}

Objective: To evaluate levofloxacin efficiency for treatment of chronic suppurative otitis media in sample of Iraqi patients.

Methods: This is a prospective study which includes 50 patients of different age groups diagnosed with CSOM. Aural toilet and otosporin ear drop performed in clinic, then levofloxacin prescribed as single oral tablet daily for 4-6 weeks. Patients were examined every 2 weeks for 8 weeks and then once by month for 6 months to evaluate the efficiency of treatment.

Results: Forty patients (80\%) showed complete dryness and healing. Discharge decreased upon the visits with more dryness observed after 4 weeks of treatment. Signs of healing and tympanic perforation closure apparently occur about 1 month from the initial treatment in 32 patients $(80 \%$ of successful treatment). Culture sensitivity tests results were Pseudomonas aeruginosa and Klebsiella species in discharge materials.

Conclusion: Levofloxacin is a safe and effective drug for the treatment of CSOM and promising treatment for CSOM in combination with aural toilet. The main species of microorganism detected were P. aeruginosa and Klebsiella.

Keywords: Otitis media, Levofloxacin, Fluoroquinolone.

(c) 2017 The Authors. Published by Innovare Academic Sciences Pvt Ltd. This is an open access article under the CC BY license (http://creativecommons. org/licenses/by/4. 0/) DOI: http://dx.doi.org/10.22159/ajpcr.2017.v10i9.18147

\section{INTRODUCTION}

Chronic suppurative otitis media (CSOM) is a chronic inflammation of the middle ear and mastoid cavity, with recurrent ear discharges (otorrhea) and tympanic perforation [1]. Tympanic perforations with a discharge for periods from 6 weeks to 3 months, despite medical treatment, were diagnosed as CSOM [2].

The infection may occur during childhood, with a peak around 2 years started as acute otitis media [3]. Upper respiratory infection, which is common during childhood, poor socioeconomic status, and poor hygiene and nutrition, maybe accounts for CSOM development [4]. This may explain the high prevalence of CSOM in the developing countries. In addition, gene abnormalities have implicated as host risk factors for CSOM [5]. Mild-to-moderate hearing impairment among children and young people, meningitis, and brain abscess are some complications of CSOM that impair patients' hearing and potentially fatal [6].

Pathogenesis of CSOM is complex and multifactorial. In adequate treatment of middle ear infection may cause epithelial migration over the edges of perforation, in addition to other factors like immunological and genetic factors Eustachian tube morphology, and types of bacterial isolate and biofilm formation play a role in CSOM pathogenesis $[7,8]$

Treatment of CSOM aimed to improve symptoms, heal perforations, and reduce complications, with minimum adverse effects. various types of treatment protocol used like: topical antibiotics plus corticosteroids, oral antibiotics plus topical antiseptics or systemic antibiotic alone $[9,10]$. Ear cleansing and surgical treatment may be a choice of treatment in certain cases[11]. Isolates of bacteria determine the use of proper antibiotics. Since the commonly isolates are Pseudomonas aeruginosa and Staphylococcus aureus [12], fluoroquinolones such as ciprofloxacin and levofloxacin show greater potency against Pseudomonas species according to Ikeda et al. [13]. levofloxacin is one of fluoroquinolone broad spectrum antibiotics, that is well absorbed, widely distributed through body tissue with long period of action that allow single dosing. In addition to that levofloxacin is available for intravenous and oral routs $[13,14]$. It acts by blocking bacterial DNA synthesis through inhibition of bacterial topoisomerase II [14]. Common adverse effects are nausea, vomiting, diarrhea, and gastric upset. Levofloxacin is one of the respiratory fluoroquinolones which is active against upper and lower respiratory tract infections. According to the previous facts, the purpose of the present study is to evaluate the efficiency of oral levofloxacin in CSOM treatment in a sample of Iraqi patients.

\section{METHODS}

This is a prospective study conducted between September 2015 and December 2016 including patients referred to a consultant, Auto Laryngeal Clinic in Al-Hilla General Teaching Hospital.

Fifty patients of different age groups were included (Table 1). 80\% of patients were rural and $20 \%$ urban with failed treatment history. All patients had chronic mastoiditis and $100 \%$ conductive hearing loss between 40 and $70 \mathrm{~dB}$. Older aged patients already have sensory neural hearing loss in addition to conductive hearing loss (Table 2).

\section{Inclusion criteria}

Patients with CSOM signs and symptoms including offensive ear discharge and tympanic eardrum perforation with more than 6-week history were included in the study.

\section{Exclusion criteria}

Patients with CSOM symptoms less than 6 weeks history and/or patients with discharge without perforation or perforation without discharge were excluded.

\section{Diagnosis}

All patients were clinically examined by tympanoscope, and diagnosis of CSOM was confirmed by computerized tomography which reveals 
sclerosis mastoid air cells, granulomatous tissue, polyps, and erosion ossicles. culture sensitivity test performed to identify micro organism species involved.

\section{Study design}

After confirmed diagnosis, patients with COSM treated as follows.

Local aural toilet by either electrical suction or using cotton wool swabs with iodine $4 \%$ for cleaning was performed and then otosporin drops applied topically in the clinic and each visit; after that, levofloxacin was prescribed as a single oral daily dose for 4-6 weeks. Patients were examined every 2 weeks for 8 weeks and then once by month for 6 months to evaluate the efficiency of treatment. Patients who develop adverse effect during the treatment period of 6 weeks were asked to stop medical treatment for 1 week and then start again as a single oral daily dose for the rest of the treatment period.

Culture sensitivity test was made in accordance with the standard laboratory procedures depending on minimum inhibitory zone diameters.

\section{Drugs}

Levofloxacin tablets of 500 mg strength (Sanofi-Aventis,France).

\section{Ethical statement}

The study protocol was reviewed and approved by the Institutional Review Board of Al-Hilla Teaching Hospital and Ethical Board of Medical College of Babylon University. Written informed consent from patients was obtained.

\section{RESULTS}

At the end of the study period from 50 treated patients, 40 patients show complete dryness and healing as expressed in Table 3. Discharge decreased upon visits with more dryness observed after 4 weeks of treatment. Signs of healing and tympanic perforation closure apparently occur about 1 month from initial treatment in 32 patients.

$20 \%$ of patients who do not respond to medical treatment for 6 weeks referred for surgical treatment. Four women and six men of 50-70 years age group were not responded to medical treatments. $4(85 \%)$ patients with diabetes mellitus were from those who not respond to treatment.

Adverse drug reactions were mild including gastric irritation, nausea, or vomiting mainly experienced in elderly patients after 4 weeks of continuous medical treatment; they were asked to stop treatment for 1 week and antacid prescribed to them and then start again for the rest of the period. Otherwise, levofloxacin was well tolerated by other patients during the treatment period of 6 weeks. Culture sensitivity tests results were $P$. aeruginosa and Klebsiella species in most of patients' discharge materials.

\section{DISCUSSION}

CSOM is one of the life-disabling diseases that followed with serious complications. Treatment may be medical or surgical. Since CSOM is inflammatory disease with bacterial inhabitant, treatment focused on antibiotics with bactericidal activity to eradicate pathogenic bacteria and allow dryness of discharge to promote healing. Selection of appropriate antibiotic is important putting in consideration efficiency, safety, and compliance of patients.

The current study focused on aural toilet and medical treatment using one of the respiratory fluoroquinolones levofloxacin as an effective systemic treatment according to many studies than aural toilet alone or with different types of antibiotics used systemically or topically [15-17]. Of 50 patients included in the current study, 80\% of them successfully treated with levofloxacin for 6-week treatment with great number within 4 weeks of treatment. The result of this study shows that levofloxacin is a proper choice and effective
Table 1: Number of patients according to age group

\begin{tabular}{ll}
\hline Age (years) & Number of patients \\
\hline $16-20$ & 15 \\
$20-40$ & 25 \\
$40-60$ & 9 \\
$>60$ & 2 \\
\hline
\end{tabular}

Sample size, 50 patients

Table 2: Clinical criteria of patients included in this study

\begin{tabular}{ll}
\hline Criteria & Percentage of patients \\
\hline Sex & $65 \%$ males - 35\% females \\
Conductive hearing loss & $100 \%$ \\
Diabetes mellitus & $10 \%$ \\
Computed tomography finding & $100 \%$ positive \\
Chronic mastoiditis & $100 \%$ \\
Cholesteatoma & $0 \%$ \\
Discharge & $100 \%$ \\
Patients origin & $80 \%$ rural $20 \%$ urban \\
Previous antibiotic treatment & $100 \%$ \\
\hline Data expressed as percentages &
\end{tabular}

Table 3: Percentage of patients with complete discharge dryness and healing during follow-up visits

\begin{tabular}{lll}
\hline $\begin{array}{l}\text { Time for initial } \\
\text { treatment }\end{array}$ & $\begin{array}{l}\text { Number of patients } \\
\text { with complete dryness }\end{array}$ & Percentages \\
\hline 2 weeks & 3 patients & 7.5 \\
4 weeks & 32 patients & 80 \\
6 weeks & 5 patients & 12.5 \\
\hline
\end{tabular}

especially against $P$. aeruginosa and Klebsiella which detected in culture sensitivity test. Species of microorganism detected in our study agrees with Rath etal.,2016 [18] and Renukanada etal., [19]. A previous study by Hwang et al., 2015 [20] which compared the efficiency of vancomycin and arbekacin found no significant difference in efficiency but with more adverse effect with vancomycin in methicillin-resistant $S$. aureus (MRSA)-associated CSOM. While, in the current study, the main species detected were P. aeruginosa and Klebsiella not MRSA. Levofloxacin allows single dosing regimen, which is much easier for patients especially for a long period with lower mistake chances as levofloxacin has long clearance half-life [20]. Levofloxacin $500 \mathrm{mg}$ shows mild adverse reaction during the study period, which occurs in elderly patients only. Elderly patients usually have impairment in elimination process that may cause accumulation of drug leading to adverse reactions; this could be an explanation although we did not confirm by creatinine clearance test. Failure in medical treatment in this study was about 20\% (10) patients, four of them had diabetes which means most of the diabetic patients were recorded. This finding may be due to the impact of diabetes mellitus on microcirculation, which decreases drug concentration in the infected area that dedicates use of other treatment modality rather than single antibiotic treatment.

Most of the patients included in the study were rural patient $(80 \%)$ with low socioeconomic status (Table 2) and that goes with other studies which declare the impact of lower socioeconomic status on the prevalence of CSOM [21-24].

\section{CONCLUSION}

Levofloxacin is safe and effective drug for treatment of CSOM and promising treatment for CSOM in combination with aural toilet. The main species of microorganism detected were $P$. aeruginosa and Klebsiella. 


\section{REFERENCES}

1. Kenna MA. Treatment of chronic suppurative otitis media. Otolaryngol Clin North Am 1994;27:457-72.

2. Goycoolea MV, Hueb MM, Ruah C. Otitis media: The pathogenesis approach. Definitions and terminology. Otolaryngol Clin North Am 1991;24:757-61.

3. Verhoeff M, van der Veen EL, Rovers MM, Sanders EA, Schilder AG. Chronic suppurative otitis media: A review. Int J Pediatr Otorhinolaryngol 2006;70:1-12.

4. MacIntyre EA, Heinrich J. Otitis media in infancy and the development of asthma and atopic disease. Curr Allergy Asthma Rep 2012;12(6):547-50.

5. Qureishi A, Lee Y, Belfield K, Birchall JP, Daniel M. Update on otitis media - prevention and treatment. Infect Drug Resist 2014;7:15-24.

6. Berlin IL. Chronic Suppurative Otitis Media: Burden of Illness and Management Options. Geneva, Switzerland: World Health Organization; 2004.

7. Reiss M, Reiss G. Suppurative chronic otitis media: Etiology, diagnosis and therapy. Med Monatsschr Pharm 2010;33:11-6.

8. Neeraja P, Parthasarathy T, Sudhakar M. Evaluation of different culture media for enhanced production of Pseudomonas aeruginosa (MTCC NO 2453) biomass and its proteins. Int J Pharm Pharm Sci 2016;8(11):120-3

9. Miro N, Perello E, Casamitjana F, The Spanish ENT Study Group Affiliation: From the Servicio de Otorrinolaringología, Hospital Universitario Germans Trias i Pujol. Controlled multicenter study on chronic suppurative otitis media treated with topical applications of ciprofloxacin $0.2 \%$ solution in single-dose containers or combination of polymyxin B, neomycin, and hydrocortisone suspension. Otolaryngol Head Neck Surg 2000;23:617-23.

10. Macfadyen CA, Acuin JM, Gamble C. Systemic antibiotics versus topical treatments for chronically discharging ears with underlying eardrum perforations. Cochrane Database Syst Rev 2006;1:25.

11. Mishiro Y, Sakagami M, Takahashi Y, Kitahara T, Kajikawa H, Kubo T. Tympanoplasty with and without mastoidectomy for noncholesteatomatous chronic otitis media. Eur Arch Otorhinolaryngol 2001;258:13-5.

12. Sharma K, Aggarwal A, Khurana PM. Comparison of bacteriology in bilaterally discharging ears in chronic suppurative otitis media. Indian $\mathrm{J}$ Otolaryngol Head Neck Surg 2010;62:153-7.
13. Ikeda K, Misawa S, Kusunoki T. Comparative bactericidal activity of four fluoroquinolones against Pseudomonas aeruginosa isolated from chronic suppurative otitis media. BMC Ear Nose Throat Disord 2015; 15:5.

14. Pham L, Christensen JM, Rodriguez-Proteau R. Pharmacokinetic prediction of levofloxacin accumulation in tissue and its association to tendinopathy. Pharmacol Pharm 2013;4:121-31.

15. Katzung BG, Trevor AJ. Basic and Clinical Pharmacology. $13^{\text {th }}$ ed. Norwalk: McGraw-Hill Education; 2015. p. 1116-7.

16. Berlin IL. Chronic Suppurative Otitis Media: Burden of Illness and Management Options. Geneva, Switzerland: World Health Organization; 2004.

17. Rotimi VO, Olabiyi DA, Banjo TO, Okeowo PA. Randomised comparative efficacy of clindamycin, metronidazole, and lincomycin, plus gentamicin in chronic suppurative otitis media. West Afr J Med 1990;9:89-97.

18. Rath S, Das SR, Padhy RN. Surveillance of bacteria Pseudomonas aeruginosa and MRSA associated with chronic suppurative otitis media. Braz J Otorhinolaryngol 2017;83:201-6.

19. Renukananda GS, Santosh UP, George NM. Topical vs. Combination ciprofloxacin in the management of discharging chronic suppurative otitis media. J Clin Diagn Res 2014;8:KC01-4.

20. Hwang JH, Lee JH, Hwang JH, Chung KM, Lee EJ, Yoon YJ, et al. Comparison of arbekacin and vancomycin in treatment of chronic suppurative otitis media by methicillin resistant Staphylococcus aureus. J Korean Med Sci 2015;30:688-93.

21. Lubasch A, Keller I, Borner K, Koeppe P, Lode H. Comparative pharmacokinetics of ciprofloxacin, gatifloxacin, grepafloxacin, levofloxacin, trovafloxacin, and moxifloxacin after single oral administration in healthy volunteers. Antimicrob Agents Chemother 2000;44:2600-3

22. Daly KA, Pirie PL, Rhodes KL, Hunter LL, Davey CS. Early otitis media among Minnesota American Indians: The Little Ears Study. Am J Public Health 2007;97:317-22.

23. Zhang Y, Xu M, Zhang J, Zeng L, Wang Y, Zheng QY. Risk factors for chronic and recurrent otitis media-a meta-analysis. PLoS One 2014;9:e86397.

24. Ramanna MK, Ruckmani A, Janti SS, Eerike M, Prabu RL. Burden of therapy in patients suffering from diabetes mellitus and hypertension. Int J Pharm Pharm Sci 2017;9(5):210-5. 